\title{
Dielectric properties of paraffin wax emulsion/copper azole compound system treated wood
}

\author{
Yuqing Liao ${ }^{(1)}$, \\ Erni Ma ${ }^{(1)}$, \\ Ru Liu ${ }^{(2)}$
}

\begin{abstract}
In order to investigate the interactions among the waterproof agent, preservative and wood, the dielectric relaxation was measured for untreated wood and wood samples treated with different paraffin wax emulsion/copper azole (CA) compound systems at oven-dried and air-dried state, respectively. The ColeCole plot analysis was then conducted and the results were as follow. At ovendried state $\left(-60{ }^{\circ} \mathrm{C}\right)$, the dielectric characteristics of paraffin wax emulsion treated wood were basically the same as those of untreated wood; CA treatment increased the dielectric constant but decreased the dielectric loss factor and the trends of these two characteristic parameters were more remarkable at higher CA concentration; the dielectric properties of compound system treated wood under C4A grade were similar to those of CA treated wood but an increase in impregnation of paraffin wax emulsion gave rise to decreased dielectric constant and increased loss factor. At air-dried state $\left(20^{\circ} \mathrm{C}, 65 \% \mathrm{RH}\right)$, compared with untreated samples, both the dielectric constant and loss factor were lower in waterproofing agent treated wood and these parameters reduced with increasing waterproofing agent concentration; for CA treated samples, the values of dielectric parameters increased and the trend was similar to those treated with the compound system under C4A grade.
\end{abstract}

\section{Keywords: Wood, Paraffin Wax Emulsion, Copper Azole, Dielectric Properties}

into water-borne preservatives during wood treatment to obtain wood products with both effective decay resistance and dimensional stability. Wang et al. (2011) found that the mixture of alkaline copper quaternary (ACQ) and paraffin emulsion prepared by certain natural surfactants, such as tween and span, could dramatically promote the resistance against water for treated wood. Later in our previous works, the compound system of paraffin wax emulsion and copper azole (CA) was developed with high stability, and the treated wood performed well in waterproofing (Wang et al. 2014), anti-mould and antiblue stain tests (Zhong et al. 2014), and decay fungi resistance (Liu et al. 2018). However, there is a lack of research on the micro-mechanism of the interaction among paraffin wax emulsion, CA and wood molecules.

Dielectric relaxation has been proved to be an effective method to reveal the physical and chemical interaction between wood and small molecules such as water, formaldehyde and acetic acid (Zhao et al. 1994a, 1994b, Cao \& Zhao 2001, Khan et al. 2000, Hou et al. 2004, Sahin \& Ay 2004, Sugimoto et al. 2005, Wang et al. 2016). The process of dielectric relaxation reflects how the polarization intensity of sample varies with the frequency and temperature change of alternating electric field. The main parameters of dielectric properties are dielectric constant $\left(\varepsilon^{\prime}\right)$ and dielectric loss factor $\left(\varepsilon^{\prime \prime}\right) . \varepsilon^{\prime}$ is defined as a measure of the material's ability to become polar- ized and to store charge when an external electric field is applied to it through parallel plates; $\varepsilon^{\prime \prime}$ is defined as the measure of the electrical energy which is converted into heat (Sreekumar et al. 2012). The two parameters are both related to the reorientation of dipoles. For oven-dried wood, the most important dipole of wood was the methylol groups in amorphous region of wood cell wall, while for air-dried wood, the adsorbed water dominated. There are many factors affecting both $\varepsilon^{\prime}$ and $\varepsilon^{\prime \prime}$. The most important two factors are frequency and temperature. At low frequency, complete orientation of the dipoles are possible leading to high $\varepsilon^{\prime}$. However, at high frequency, the molecular vibrations are high and hence complete orientation of dipoles does not take place and therefore the $\varepsilon^{\prime}$ decreases as frequency increases. For $\varepsilon^{\prime \prime}$, the situation is complex. At low frequency, dipoles are possible to be aligned directly to the electron field and low heat is produced. At high frequency, dipoles fail to orient and the heat is still low. Therefore, as frequency increases, a peak of $\varepsilon^{\prime \prime}$ exists where there is the phase lag of dipoles orientation against the electron field change. The temperature affects the motivation of dipole molecules. With the increase of temperature, the motivation of dipole molecules becomes easier. Thus, the $\varepsilon^{\prime}$ increases while $\varepsilon$ " decreases.

The objective of this study was to use dielectric relaxation approach to further analyse the interactions among the waterproof agent, preservative and wood, as 
well as the mutual effect between these two chemicals in treated wood on their penetration and existing condition under oven-dried and air-dried conditions, respectively. The results were expected to shed some lights on the various macroscopic properties of the compound system treated wood at a microscopic level, and to provide favourable scientific evidences and theoretical supports for the manufacture of waterproofing preservative-treated wood. Besides, the results of this study could found a relationship between dielectric property and other properties of modified wood, such as the durability. Therefore, in practice, the durability of the wood could be quickly known by calculating the dielectric parameters without destroying the wood.

\section{Materials and methods}

\section{Materials}

Defect-free sapwood from Southern pine (Pinus spp.) was selected as the test material and cut into samples with a size of 10 $\mathrm{mm}(\mathrm{L}) \times 10 \mathrm{~mm}(\mathrm{R}) \times 3 \mathrm{~mm}(\mathrm{~T})$ after airdrying. The samples were divided into nine groups according to different treatments (Tab. 1). Wood preservative was CA-B, with mass fraction of two effective components of copper and triazole at $10.4 \%$, purchased

Tab. 1 - Group of wood samples according to the treatment applied.

\begin{tabular}{llcc}
\hline & & \multicolumn{2}{c}{ Concentration / \% } \\
\cline { 3 - 4 } No. Group & $\begin{array}{c}\text { Paraffin } \\
\text { wax } \\
\text { emulsion }\end{array}$ & CA \\
\hline 1 & control & 0 & 0 \\
2 & $0.5 \% \mathrm{~W}$ & 0.5 & 0 \\
3 & $1.0 \% \mathrm{~W}$ & 1.0 & 0 \\
4 & $0.3 \% \mathrm{C}$ & 0 & 0.3 \\
5 & $0.5 \% \mathrm{C}$ & 0 & 0.5 \\
6 & $0.5 \% \mathrm{~W} / 0.3 \% \mathrm{C}$ & 0.5 & 0.3 \\
7 & $1.0 \% \mathrm{~W} / 0.3 \% \mathrm{C}$ & 1.0 & 0.3 \\
8 & $0.5 \% \mathrm{~W} / 0.5 \% \mathrm{C}$ & 0.5 & 0.5 \\
9 & $1.0 \% \mathrm{~W} / 0.5 \% \mathrm{C}$ & 1.0 & 0.5 \\
\hline
\end{tabular}

Tab. 2 - Average moisture content of wood samples at air-dried state $\left(20^{\circ} \mathrm{C}\right.$, $65 \%)$.

\begin{tabular}{clc}
\hline No. & Group & $\begin{array}{c}\text { Average moisture } \\
\text { content (\%) }\end{array}$ \\
\hline 1 & control & 10.81 \\
2 & $0.5 \% \mathrm{~W}$ & 10.59 \\
3 & $1.0 \% \mathrm{~W}$ & 10.21 \\
4 & $0.3 \% \mathrm{C}$ & 12.21 \\
5 & $0.5 \% \mathrm{C}$ & 12.81 \\
6 & $0.5 \% \mathrm{~W} / 0.3 \% \mathrm{C}$ & 11.96 \\
7 & $1.0 \% \mathrm{~W} / 0.3 \% \mathrm{C}$ & 11.53 \\
8 & $0.5 \% \mathrm{~W} / 0.5 \% \mathrm{C}$ & 12.72 \\
9 & $1.0 \% \mathrm{~W} / 0.5 \% \mathrm{C}$ & 12.49 \\
\hline
\end{tabular}

from the Guangzhou Xingyue Wood Preservative Ltd. Co., China. Paraffin wax emulsion waterproofing agent was prepared in the laboratory by natural surfactants of alkyl glycoside and span with a solid content of $25 \%$.

Wood treatment by compound systems According to use categories $\mathrm{C}_{3}$ and $\mathrm{C}_{4} \mathrm{~A}$, two concentrations of $0.3 \%$ and $0.5 \%$ for $C A$ were determined to reach the corresponding minimal retention levels, which were labelled as $0.3 \% \mathrm{C}$ and $0.5 \% \mathrm{C}$, respectively. In addition, the concentrations of paraffin wax emulsions used in this study were $0.5 \%$ and $1.0 \%$, marked as $0.5 \% \mathrm{~W}$ and $1.0 \% \mathrm{~W}$, respectively. Sample grouping and the formula for each treatment group are listed in Tab. 1. Wood samples were impregnated via a full-cell process. Specifically, the samples were first exposed to a vacuum condition at $-0.01 \mathrm{MPa}$ for $30 \mathrm{~min}$, then submerged in treated liquid under a pressure of $0.5 \mathrm{MPa}$ for $1 \mathrm{~h}$. After impregnation, the pressure was released and the samples were collected, wiped with tissue papers, covered by plastic films, and kept at room temperature for 2 days.

\section{Moisture content control}

\section{Oven-dried condition}

Treated samples were placed in the open air for one week. After that, they were dried in the oven at $103 \pm 2{ }^{\circ} \mathrm{C}$ until constant weight. The samples were move into a desiccator at room temperature, waiting for the dielectric test.

\section{Air-dried condition}

In order to reach air-dried moisture content, these treated samples were placed in a hermetic jar filled with saturated solution of sodium bromide in a temperature chamber maintained at $20 \pm 2{ }^{\circ} \mathrm{C}$, which corresponds to the relative humidity of $65 \pm 2 \%$. The average moisture contents of different treated samples at air-dried state are shown in Tab. 2.

\section{Measurement of dielectric properties}

Dielectric properties of specimens were measured with the Agilent $4294 A^{\oplus}$ Precision Impedance Analyser (Agilent Technologies, Santa Clara, CA, USA) with plate electrodes at a diameter of $32 \mathrm{~mm}$ (image is shown in Fig. S1 - Supplementary material). The measurement was performed within a temperature range from -60 to 20 ${ }^{\circ} \mathrm{C}$ at an interval of $20{ }^{\circ} \mathrm{C}$. Because of the very short testing time (few minutes), the change in the original moisture of the wood samples could be ignored. The selected frequencies were $100 \mathrm{~Hz}, 316 \mathrm{~Hz}, 1$ $\mathrm{kHz}, 3.16 \mathrm{kHz}, 10 \mathrm{kHz}, 31.6 \mathrm{kHz}, 100 \mathrm{kHz}, 316$ $\mathrm{kHz}$ and $1 \mathrm{MHz}$, respectively, as they corresponded to 2.0, 2.5, 3.0, 3.5, 4.0, 4.5, 5.0, 5.5 , and 6.0 on a logarithm scale, respectively. The capacitance value $\left(C_{p}\right)$ and the dielectric loss factor $\left(\varepsilon^{\prime \prime}\right)$ were directly obtained, and the dielectric constant $\left(\varepsilon^{\prime}\right)$ was acquired according to the following formula (eqn. 1):

$$
\varepsilon^{\prime}=t_{a} C_{p} /\left(A \varepsilon_{0}\right)
$$

where $t_{\mathrm{a}}$ is the mean thickness of specimens, $C_{p}$ is the capacitance value, $A$ is the contact area between the wood sample and the electrode plates, $\varepsilon_{0}$ is the permittivity of vacuum $\left(8.845 \cdot 10^{-12} \mathrm{~F} / \mathrm{m}\right)$.

Cole-Cole plot analysis (Cole \& Cole 1941) was applied to investigate the dielectric relaxation strength of studied samples, based on the following equation (eqn. 2)

$$
\varepsilon^{*}=\varepsilon_{\infty}+\left(\varepsilon_{s}-\varepsilon_{\infty}\right) /\left[1+\left(\mathrm{i} \omega \tau_{0}\right)^{\beta}\right]
$$

where $\varepsilon^{*}$ is the complex dielectric constant; $\varepsilon_{\mathrm{s}}$ is the static dielectric constant, that is, the dielectric constant at extreme low frequency; $\varepsilon_{\infty}$ is the optic dielectric constant, namely the dielectric constant at extreme high frequency; $\left(\varepsilon_{\mathrm{s}}-\varepsilon_{\infty}\right)$ is thus defined as the relaxation strength, representing the magnitude of relaxation; $\omega$ is the angular frequency, $\omega=2 \pi f \cdot \tau_{0}$ represents average relaxation time; $\beta(0<\beta \leq 1)$ is the parameter which characterizes the relaxation time distribution: the broader relaxation time distribution is, the less $\beta$ value becomes (Torgovnikov 1993).

In this work, Originpro ${ }^{\mathrm{TM}} 2016$ (OriginLab Corp., Northampton, MA, USA) was used during plotting by reconstructing eqn. 2 into $y=\left[R^{2}-(x-a)^{2}\right]^{0.5}+b$, with $a, b$ being the centre coordinate and $R$ as radius of the arc.

\section{Results and discussion}

\section{Dielectric relaxation under oven-dried condition}

\section{Dielectric parameters of untreated wood}

Dielectric frequency and temperature spectra for oven-dried untreated wood are compared in Fig. 1. As shown in Fig. 1a, the $\varepsilon^{\prime}$ value decreases with increasing frequency. $\varepsilon^{\prime}$ denotes the amount of dipoles participating in reorientation (Nelson 2004, George et al. 2013), and the primary dipoles in the untreated oven-dried wood samples are methylol groups in the amorphous region of wood cell walls. With increasing frequency, these dipoles were difficult to reorient in alternating electric field, thereby reducing the value of dielectric constant (Ma \& Zhao 2012). Fig. S2a (Supplementary material) shows the sketch image of methylol groups reorientation in oven-dried untreated wood in the alternating electric field. There is only a peak for dielectric loss factor at $-60{ }^{\circ} \mathrm{C}$ (Fig. 1b) and this peak disappears with increasing temperature, because the peak moves to a higher frequency with increasing temperature, which is beyond the testing scope. It was suggested that this peak was caused by the reorientation of the dipoles that cannot completely synchronize with the changing electric fields as presented in the introduction 
Fig. 1 - The frequency $(a, b)$ and temperature spectra (c,d) of $\varepsilon^{\prime}(a, c)$ and $\varepsilon^{\prime \prime}$ (b, d) for untreated wood at oven-dried state.
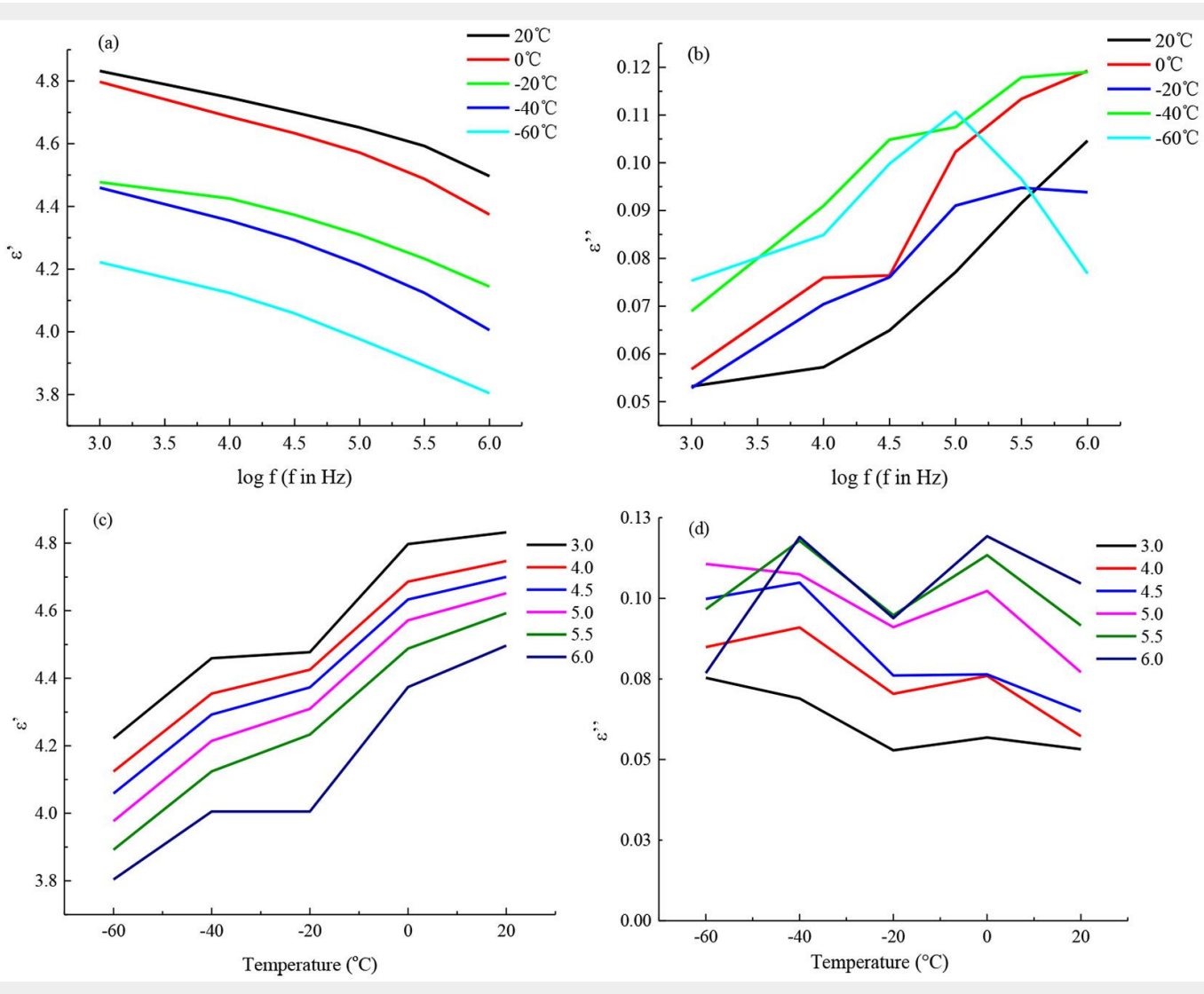

part (Ma \& Zhao 2012). Therefore, for a better investigation, dielectric relaxation process of oven-dried samples at $-60{ }^{\circ} \mathrm{C}$ was chosen.

On the other hand, as shown in Fig. 1c, the $\varepsilon^{\prime}$ increases with increasing temperature, from 3.8-4.2 when the temperature is $-60{ }^{\circ} \mathrm{C}$ to $4.5-4.8$ when the temperature reaches $20{ }^{\circ} \mathrm{C}$. This is because the higher temperature would intensify the movement of wood molecules, giving rise to more reorientation of dipoles in alternating electric field and a higher value of dielectric constant (Ma \& Zhao 2012). It can be seen from Fig. 1d that there are two obvious peaks in the spectrum, representing two types of dielectric relaxation processes which are designated here as relaxation process R-I and relaxation process R-II, respectively. R-I appears in the low temperature region with the peak at around $-40{ }^{\circ} \mathrm{C}$. This had been previously reported and was attributed to reorientation the of methylol groups (Norimoto \& Yamada 1970, Norimoto 1976) described above. R-II occurs at $0{ }^{\circ} \mathrm{C}$, which was not observed on wood in the literature. The reason may be related to the method of sample preparation. In their researches, samples were extracted to remove wood extractives prior to dielectric measurement. Therefore, it is reasonable to relate R-II to the contribution of the solvent removable extractives present in wood (Cao et al. 2007).

\section{Dielectric parameters of paraffin wax emulsion treated samples}

The frequency spectra of $\varepsilon^{\prime}$ and $\varepsilon^{\prime \prime}$ for paraffin wax emulsion treated samples at oven-dried state $\left(-60{ }^{\circ} \mathrm{C}\right)$ are presented in Fig. $2 a$ and Fig. 2b. The dielectric curves of $\varepsilon^{\prime}$ and $\varepsilon^{\prime \prime}$ for paraffin wax emulsion treated samples are roughly the same as those of untreated samples. It is apparent that the $\varepsilon^{\prime}$ for all the three groups decreases with increasing frequency and their maximal dielectric loss factors are nearly the same, peaking around $100 \mathrm{kHz}$. Slightly decreased $\varepsilon^{\prime}$ and $\varepsilon^{\prime \prime}$ values are observed in paraffin wax emulsion treated samples for all frequencies. This is because primarily the paraffin is physically adsorbed on the internal surface of wood cell walls instead of chemically reacting with the hydroxyls in wood substances, which hindered little to the diopoles of methyoxyl (Zhong et al. 2014). Therefore, waterproofing agent almost had little influence on the dielectric properties of wood under anhydrous state.

\section{Dielectric constant and dielectric loss \\ factor of CA treated samples}

Fig. $2 \mathrm{C}$ shows that, at a given frequency, the value of $\varepsilon^{\prime}$ for CA treated samples is higher than that of untreated ones and this trend becomes greater as the concentration of the preservative rises. It can be speculated there was ionic polarization caused by a portion of copper ions of CA in the alternating electric field, leading to a higher dielectric constant for CA treated wood and this value of $\varepsilon^{\prime}$ would increase with the increase of copper ions (sketch images are shown in Fig. S2b - Supplementary material).

Fig. 2d compares the $\varepsilon^{\prime}$ between un- treated and CA treated samples under anhydrous state $\left(-60{ }^{\circ} \mathrm{C}\right)$. The $\varepsilon^{\prime \prime}$ values of $0.3 \% \mathrm{C}$ and $0.5 \% \mathrm{C}$ groups are lower than that of the control. Besides, although the maximum value of $\varepsilon^{\prime \prime}$ of $0.3 \%$ CA treated group shows the same location at $100 \mathrm{kHz}, 0.5 \%$ CA increases to high frequency region. According to earlier research (Zhong et al. 2014), the number of copper ions in CA treated wood would react with methylol groups in the amorphous region of wood cell walls, causing less reorientation of methylol groups. On the other hand, copper ions would exert steric hindrance on the methylol groups around which had difficulties in reorientation as a result. The higher content of copper ions, the more difficult of reorientation of methylol groups took place. These are the reasons why decreased value of $\varepsilon$ " and shifted maximum value at high frequency region are obtained in CA treated groups.

\section{Dielectric constant and dielectric loss factor of compound system treated samples}

As shown in Fig. 2e, compared with untreated samples, the $\varepsilon^{\prime}$ of $0.5 \% \mathrm{C} / 0.5 \% \mathrm{~W}$ is higher. This is in accordance with the presence of copper ions. However, increase of paraffin wax emulsion concentration slightly reduced the $\varepsilon^{\prime}$ value of sample treated with the compound system. Based on the results from a previous study (Wang et al. 2014), the impregnation of waterproofing agent would prevent a few copper ions from penetrating into wood cell walls. In Fig. 2e, it can be seen that the di- 
electric constant of compound system treated wood is basically the same as that of the control when the concentration of paraffin wax emulsion is $1 \%$. This can be interpreted as the impregnation of waterproofing agent gave rise to a decrease of the concentration of copper ions in treated samples, weakening the intensity of ionic polarization.

In Fig. 2f, compared with the $\varepsilon^{\prime \prime}$ between untreated and compound system treated samples, the peak of the samples with compound system treatment is a little lower than that of untreated samples, which was caused by the decreased reorientation of methylol groups that had been bonded with the copper ions in the compound system to form complex. On the other hand, the impregnation of paraffin wax emulsion at higher concentration blocked the formation of complex between copper ions and methylol groups to some extent and thus the peak value of compound system treated wood become greater with more addition of paraffin wax emulsion.

\section{Dielectric relaxation under air-dried condition}

\section{Dielectric constant and dielectric loss factor of paraffin wax emulsion treated samples}

The frequency spectra of $\varepsilon^{\prime}$ and $\varepsilon^{\prime \prime}$ of paraffin emulsion treated samples at airdried state $\left(20^{\circ} \mathrm{C}, 65 \% \mathrm{RH}\right)$ are illustrated in Fig. $3 \mathrm{a}$ and Fig. $3 \mathrm{~b}$. In air-dried state, the dipoles in wood are not only the methylol groups but also adsorbed water (a sketch image is given in Fig. S3a - Supplementary material). The decreased amplitude of paraffin wax emulsion treated samples at airdried state is much larger than that at oven-dried state. This was because the im- pregnation of paraffin wax emulsion endowed treated wood with water-resistant ability by filling up wood cell lumen and forming wax membrane on the surface of wood cell walls, which could not only hinder the movement of water molecules in cell lumen, but also prevent the moisture from being adsorbed into cell walls (Chau \& Ma 2015). Therefore, the moisture content of paraffin wax emulsion treated wood is lower than that of untreated wood after being air-dried (Tab. 2), and fewer dipoles participated in the reorientation.

Further, in Fig. $3 b$ the $\varepsilon^{\prime \prime}$ of paraffin wax emulsion treated wood declines with increasing frequency, as well as that of untreated samples. It can be suggested that the increasing frequency made it difficult for dipoles to keep up with the changes in alternating electric field, leading to a lower value of $\varepsilon^{\prime \prime}$. Because the moisture content decreased after treating with paraffin wax
Fig. 2 - The frequency spectra of $\varepsilon^{\prime}(a, c, e)$ and $\varepsilon^{\prime \prime}(b, d, f)$ for samples treated with paraffin wax emulsion (a, b), CA (c, d), and the compound systems under $\mathrm{C} 4 \mathrm{~A}$ grade $(e, f)$ at oven-dried state $\left(-60^{\circ} \mathrm{C}\right)$.
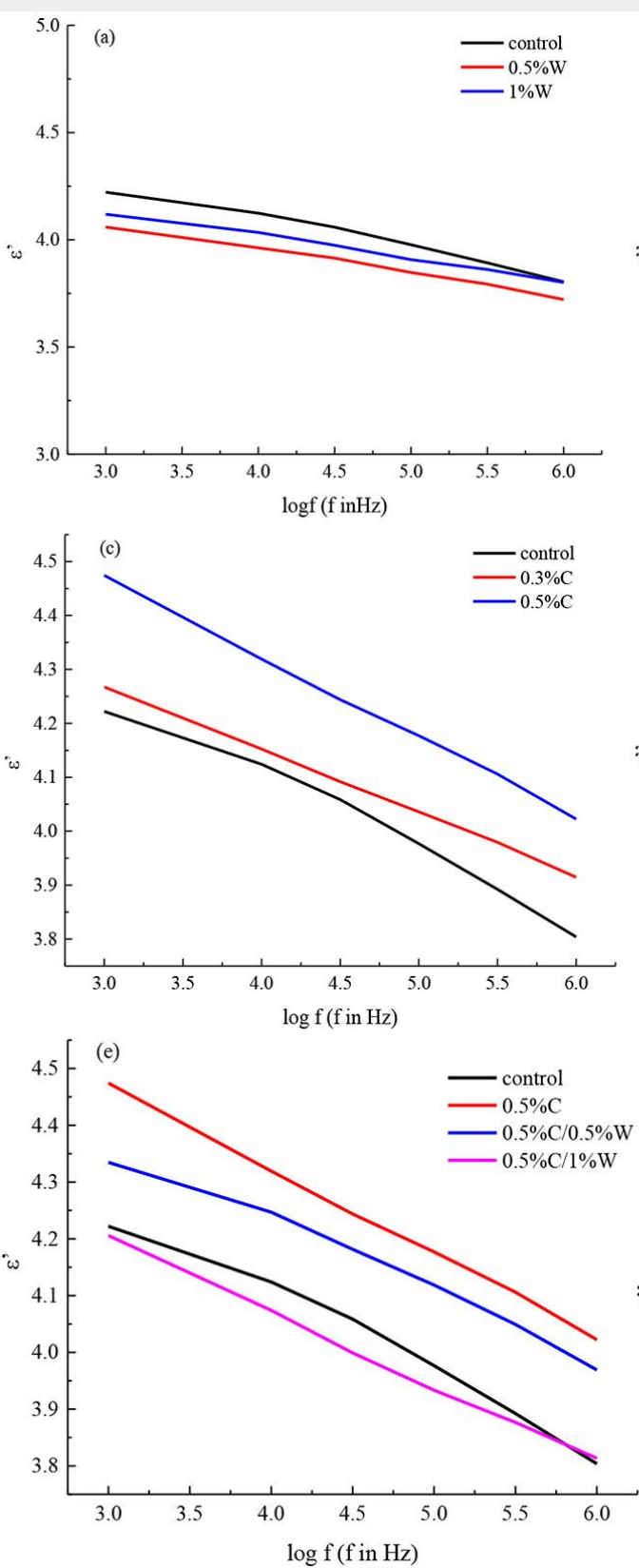
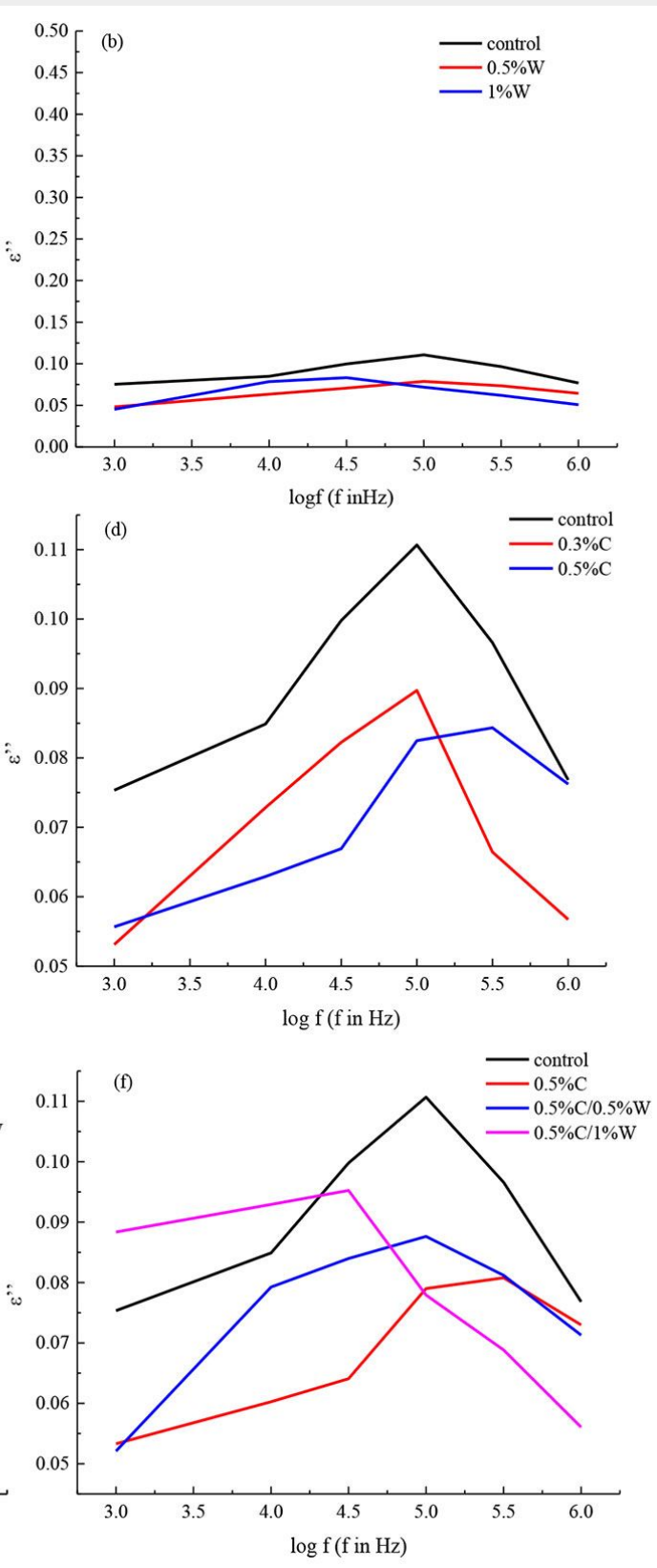

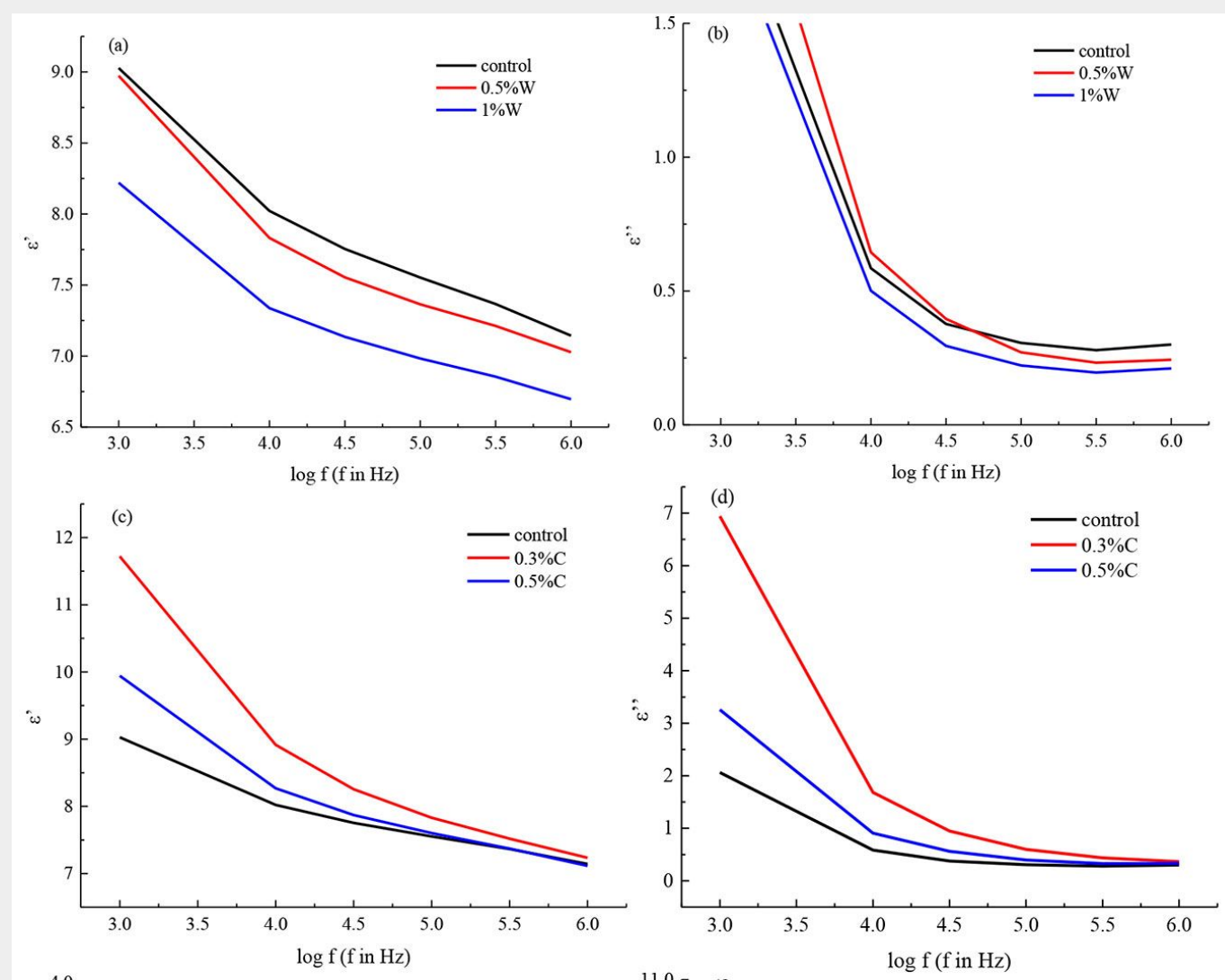

Fig. 3 - The frequency spectra of $\varepsilon^{\prime}(a, c, e)$ and $\varepsilon^{\prime \prime}(b, d, f)$ for samples treated with paraffin wax emulsion (a, b), CA (c, d), and the compound systems under $\mathrm{C} 4 \mathrm{~A}$ grade (e, f) at air-dried state $\left(20^{\circ} \mathrm{C}\right.$, $65 \% \mathrm{RH})$.
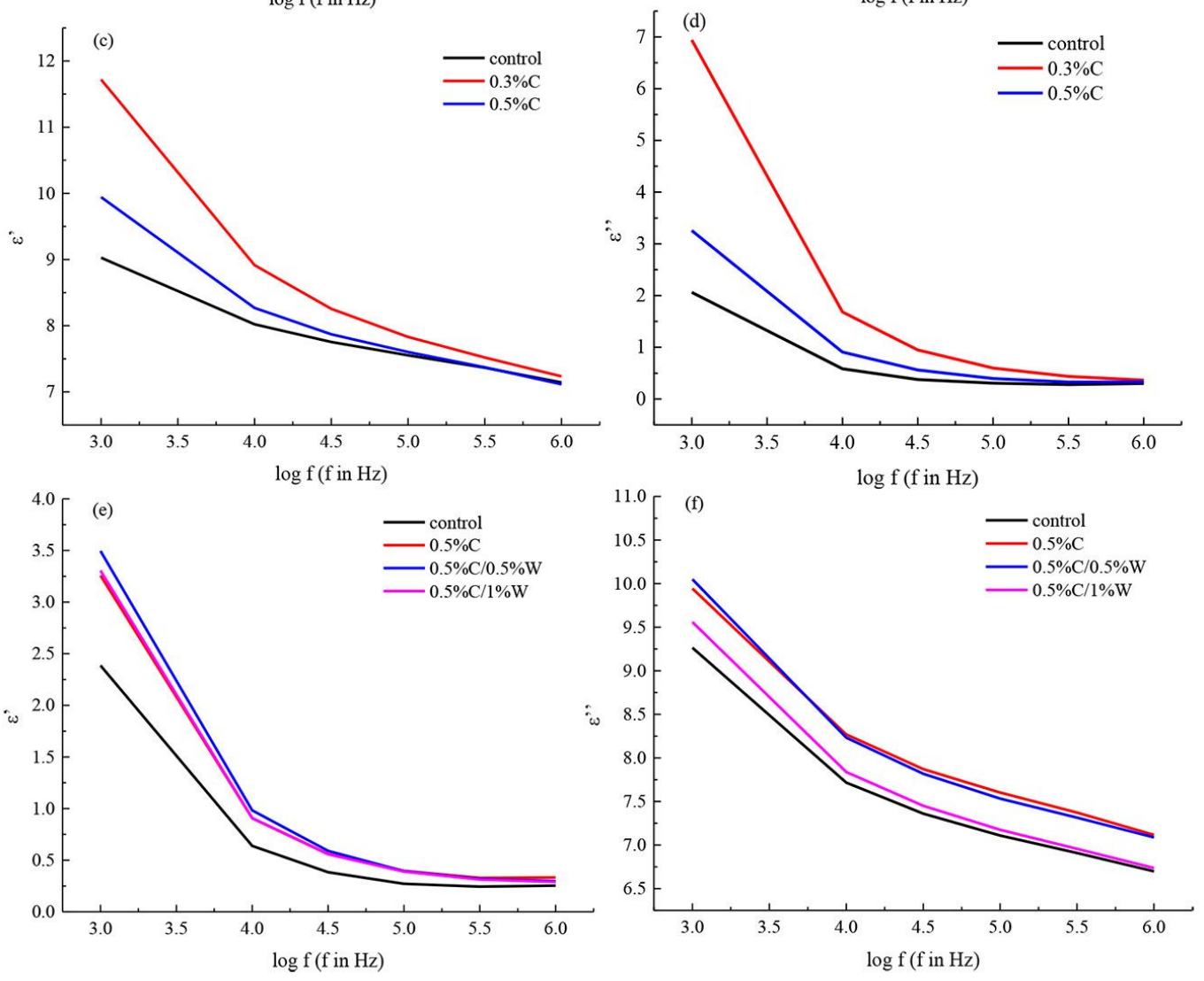

Tab. 3 - Dielectric characteristic parameters of the control and different kinds of treated samples under oven-dried state and airdried state, respectively at $20^{\circ} \mathrm{C}$.

\begin{tabular}{|c|c|c|c|c|c|c|c|c|c|c|}
\hline Parameter & Treatment & control & $0.5 \% \mathrm{~W}$ & $1.0 \% \mathrm{~W}$ & $0.3 \% \mathrm{C}$ & $0.5 \% C$ & $\begin{array}{c}0.5 \% \mathrm{~W} / \\
0.3 \% \mathrm{C}\end{array}$ & $\begin{array}{l}1.0 \% \mathrm{~W} / \\
0.3 \% \mathrm{C}\end{array}$ & $\begin{array}{c}0.5 \% \mathrm{~W} / \\
0.5 \% \mathrm{C}\end{array}$ & $\begin{array}{l}1.0 \% \mathrm{~W} / \\
0.5 \% \mathrm{C}\end{array}$ \\
\hline \multirow[t]{2}{*}{$a$} & oven-dried & 4.43 & 4.15 & 4.27 & 4.30 & 4.45 & 4.39 & 4.48 & 4.12 & 4.50 \\
\hline & air-dried & 45.43 & 29.03 & 25.06 & 117.13 & 70.25 & 73.64 & 41.95 & 63.36 & 56.90 \\
\hline \multirow[t]{2}{*}{$b$} & oven-dried & -0.95 & -0.91 & -1.03 & -1.28 & -1.66 & -0.99 & -0.87 & -1.42 & -0.86 \\
\hline & air-dried & -26.53 & -19.41 & -15.33 & -57.80 & -70.63 & -49.06 & -47.41 & -39.35 & -49.56 \\
\hline \multirow[t]{2}{*}{$R$} & oven-dried & 1.06 & 1.02 & 1.14 & 1.39 & 1.77 & 1.11 & 0.96 & 1.53 & 0.96 \\
\hline & air-dried & 46.24 & 29.23 & 23.94 & 123.56 & 94.70 & 82.44 & 58.94 & 68.34 & 70.44 \\
\hline \multirow[t]{2}{*}{$R^{2}$} & oven-dried & 0.99 & 0.99 & 1.00 & 0.99 & 1.00 & 0.99 & 0.99 & 0.99 & 0.99 \\
\hline & air-dried & 0.98 & 0.99 & 0.98 & 0.98 & 0.98 & 0.98 & 0.98 & 0.99 & 0.99 \\
\hline \multirow[t]{2}{*}{$\varepsilon_{\infty}$} & oven-dried & 3.93 & 3.69 & 3.77 & 3.76 & 3.83 & 3.88 & 4.03 & 3.63 & 4.07 \\
\hline & air-dried & 7.56 & 7.17 & 6.84 & 7.92 & 7.17 & 7.38 & 6.93 & 7.48 & 6.85 \\
\hline \multirow[t]{2}{*}{$\varepsilon_{\mathrm{s}}$} & oven-dried & 4.86 & 4.62 & 4.76 & 4.84 & 5.06 & 4.89 & 4.88 & 4.79 & 4.92 \\
\hline & air-dried & 83.30 & 50.88 & 43.27 & 226.33 & 133.32 & 139.89 & 76.96 & 119.23 & 106.95 \\
\hline \multirow[t]{2}{*}{$\varepsilon_{\mathrm{s}}-\varepsilon_{\infty}$} & oven-dried & 0.93 & 0.93 & 0.99 & 1.08 & 1.23 & 1.01 & 0.85 & 1.16 & 0.85 \\
\hline & air-dried & 75.74 & 43.71 & 36.43 & 218.41 & 126.15 & 132.51 & 70.03 & 111.75 & 101.10 \\
\hline
\end{tabular}


Fig. 4 - The ColeCole plot for paraffin wax emulsion ( $1 \%$ ) treated samples under ovendried state at $20^{\circ} \mathrm{C}$.

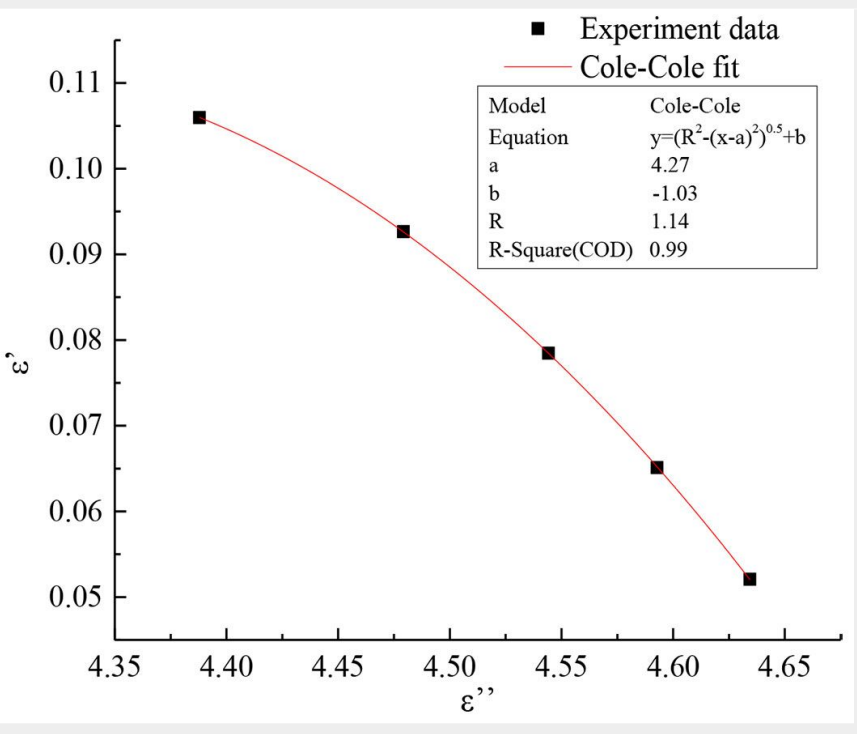

emulsion, the $\varepsilon^{\prime \prime}$ of the treated groups at $1 \% \mathrm{~W}$ is lower than that of the control.

\section{Dielectric constant and dielectric loss factor of CA treated samples}

In Fig. $3 C$, apparently, $\varepsilon^{\prime}$ of CA treated wood is higher than that of untreated wood at a specific frequency, but this value declines with increasing concentration of the preservative. Another distinct difference with the oven-dried state is that at air-dried condition, there was certain amount of adsorbed water molecules in the samples in addition to the interactions between methylol groups and CA. Based on a previous study (Wang et al. 2014), with CA treatment, these treated groups owned a higher moisture content than the control, producing more adsorbed water molecules in CA treated wood, which means more dipoles taking part in reorientation. Interestingly, as shown in Tab. 2, the CA treated samples at $0.3 \%$ and $0.5 \%$ concentration have similar moisture content, which indicates that their numbers of adsorbed water molecules are almost the same. However, the more copper ions in CA would compete with the adsorbed water simultaneously reduce the accessible primary hydroxyl groups in wood cell walls, leading to a lower number of methylol groups participating in reorientation (see the grey line in the sketch image - Fig. S3b in Supplementary material). Thus the $\varepsilon^{\prime}$ of samples treated with $0.5 \%$ CA was lower than that of wood treated with $0.3 \%$ one.

Fig. 3d shows that, compared with the control, the preservative treated wood obviously possesses a high value of $\varepsilon^{\prime \prime}$, although this value drops as the concentration of CA increases. The reason for the decreased $\varepsilon^{\prime \prime}$ was the same to that of $\varepsilon^{\prime}$, i.e., more copper ions in CA reduce the accessible primary hydroxyl groups in wood cell walls. Therefore, the generated heat of dipoles was lower.

\section{Dielectric constant and dielectric loss factor of compound system treated samples}

As shown in Fig. 3e, compared with untreated wood, samples treated with compound system have higher $\varepsilon^{\prime}$ because of their higher moisture content (Tab. 2). The trend is similar to the samples treated with the preservative agent only as mentioned above (Fig. 3c). However, compared with CA treated groups, the compound system treated samples have lower value of $\varepsilon^{\prime}$. Two reasons might account for this phenomenon: (i) the impregnation of waterproofing agent enhanced the water-resistant ability of compound system treated wood, leading to a lower number of adsorbed water molecules; (ii) the impregnation also reduced the amount of copper ions existing in wood cell walls and thus resulted in a decrease of orientation polarization inside.

In Fig. $3 f$, as expected, after being treated with $C A$, the samples have higher $\varepsilon$ " than untreated group due to more energy lost when more dipoles participated in the reorientation. However, the values of $\varepsilon^{\prime \prime}$ in the compounds were slight lower than that in the CA treated sample $(0.5 \% \mathrm{C})$. This might occur because the amount of copper ions existing in wood cell walls was reduced.

\section{Cole-Cole plots}

The Cole-Cole plots for paraffin wax emulsion $(1 \%)$ treated wood under oven-dried state at $20{ }^{\circ} \mathrm{C}$, as an example, is shown in Fig. 4. The Cole-Cole parameters for other dielectric data under oven-dried and airdried states at $20^{\circ} \mathrm{C}$ are summarized in Tab. 3. It can be seen that fitting result is good as the value of $R^{2}$ is near to 0.99. Clearly, the value of $\left(\varepsilon_{\mathrm{s}}-\varepsilon_{\infty}\right)$ for all the samples at air-dried state is much higher than that at anhydrous state. This happened because there were much more adsorbed water molecules in air-dried samples participating in reorientation as dipoles.

The comparison of relaxation strength $\left(\varepsilon_{\mathrm{s}}-\varepsilon_{\infty}\right)$ among different kinds of treated groups at oven-dried state $\left(20{ }^{\circ} \mathrm{C}\right)$ is demonstrated in Fig. 5 . It can be obtained from Fig. $5 a$ that the relaxation strength of paraffin wax emulsion treated wood is similar to that of untreated samples. In Fig. 5b, the $\left(\varepsilon_{s}-\varepsilon_{\infty}\right)$ of CA treated samples is higher than that of untreated wood and this difference is intensified at higher concentration of CA treatment. As for Fig. 5c, compared with the control, values of $\left(\varepsilon_{s}-\varepsilon_{\infty}\right)$ of samples after being treated with preservative increase but there is a light decrease in compound system treated wood as the
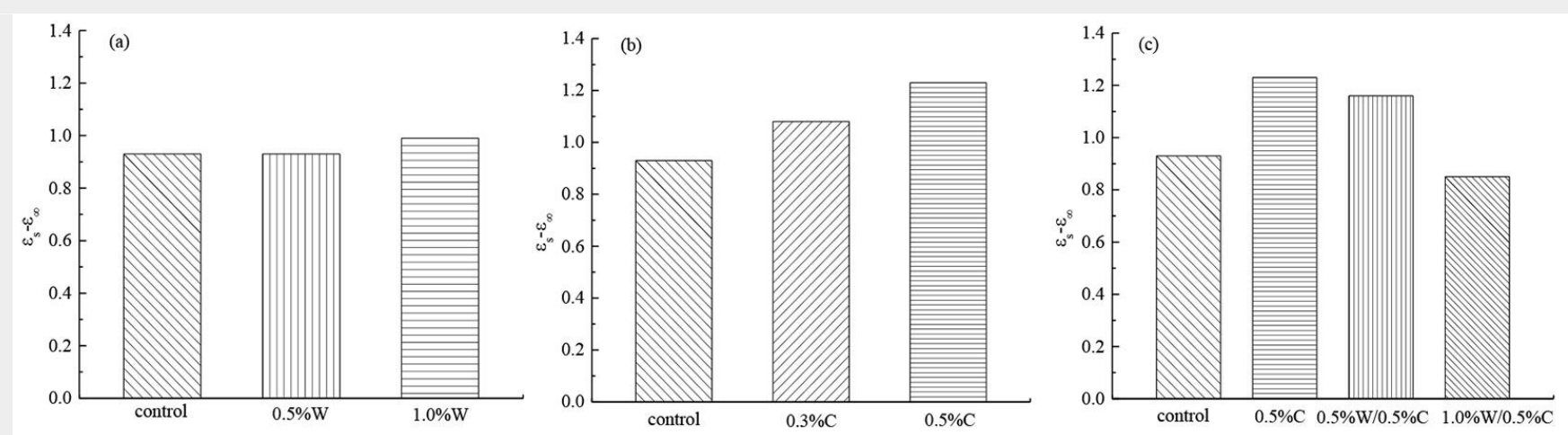

Fig. 5 - The $\left(\varepsilon_{\mathrm{s}}-\varepsilon_{\infty}\right)$ comparison among (a) paraffin wax emulsion treated samples, (b) CA treated samples and (c) the samples treated with the compound systems at C4A grade under oven-dried state at $20^{\circ} \mathrm{C}$. 


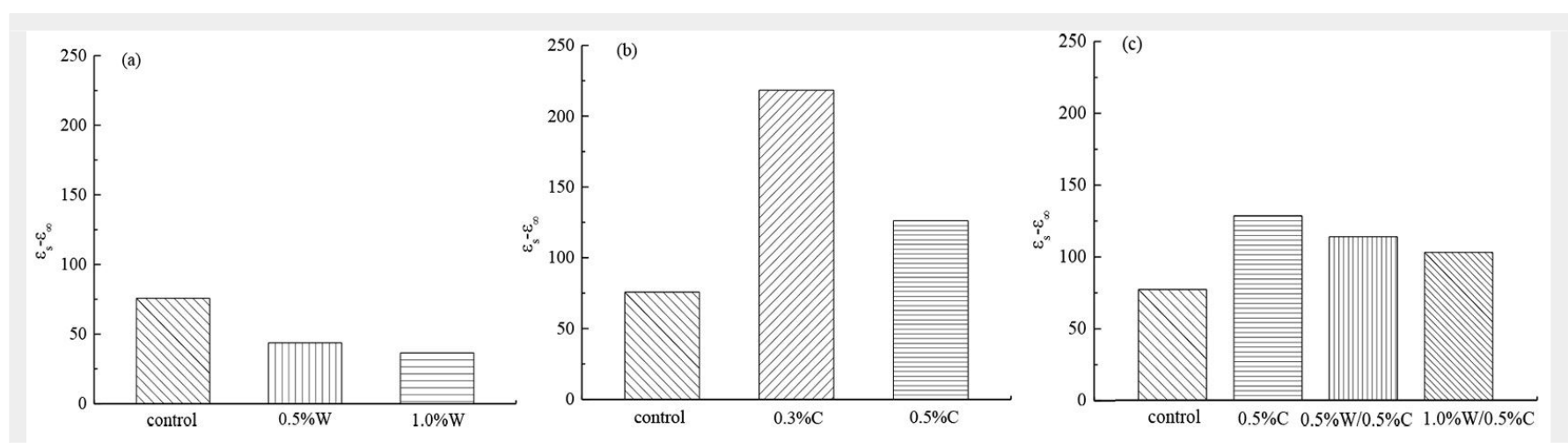

Fig. 6 - The $\left(\varepsilon_{\mathrm{s}}-\varepsilon_{\infty}\right)$ comparison among (a) paraffin wax emulsion treated samples, (b) CA treated samples and (c) the samples treated with the compound systems at $\mathrm{C} 4 \mathrm{~A}$ grade under air-dried state at $20^{\circ} \mathrm{C}$.

concentration of waterproofing agent rises. These results are in accordance with those of the dielectric constant at ovendried state as discussed above.

Fig. 6 gives the comparison of relaxation strength $\left(\varepsilon_{\mathrm{s}}-\varepsilon_{\infty}\right)$ among different kinds of treated groups at air-dried state $\left(20{ }^{\circ} \mathrm{C}\right)$. Compared with the control, paraffin wax emulsion treated wood exhibits a lower $\left(\varepsilon_{\mathrm{s}}\right.$ $\left.-\varepsilon_{\infty}\right)$ and it decreases with increasing concentration of waterproofing agent (Fig. 6a). In Fig. 6b, it can be seen that CA treated samples have a higher relaxation strength than untreated samples, but their values reveal a downward trend with a higher CA concentration. Further in Fig. $6 c$, the samples treated by $C A$ or compound system under $\mathrm{C} 4 \mathrm{~A}$ grade have stronger relaxation strength than the control group; however, the $\left(\varepsilon_{s}-\varepsilon_{\infty}\right)$ values of compound system treated groups decrease with increasing concentration of paraffin wax emulsion. Similarly, these results agree with those of the dielectric constant at airdried state analysed above.

\section{Conclusion}

The dielectric relaxation of wood (Pinus spp.) with paraffin wax emulsion, $C A$ and compound system treatments were investigated at both oven-dried $\left(-60^{\circ} \mathrm{C}\right)$ and airdried states $\left(20^{\circ} \mathrm{C}, 65 \% \mathrm{RH}\right)$ and further analysed by Cole-Cole plots. The dielectric relaxation parameters were highly related to the decay resistance of the treated wood. Due to more adsorbed water molecules participating in reorientation, the dielectric constant and relaxation strength were much higher at air-dried condition than those at oven-dried state. Because the paraffin primarily physically adsorbed on the surface of wood cells, leading to a lower moisture content of paraffin wax emulsion treated wood, the dielectric constant of waterproofing agent treated wood was lower than that of untreated samples at air-dried state. On the other hand, CA would react with methylol groups in the amorphous region of wood cell walls at oven-dried state, resulting in a reduced value of loss factor. When samples treated with the compound systems, the dielectric parameters (dielectric constant, loss factor and relaxation strength) were lower than those of CA treated samples under the same grade, which means that the impregnation of paraffin wax decreased the number of copper ions and the moisture content in compound system treated wood. Therefore, the durability of the wood in the compound system could be reduced. As a result, this study provided a non-destroyed dielectric testing method to quickly know the durability of preservative treated wood in practice.

\section{Acknowledgements}

This study was financially supported by Fundamental Research Funds for the central Universities of China (No. 2015ZCQ-CL01).

\section{References}

Cao J, Zhao G (2001). Dielectric relaxation based on adsorbed water in wood cell wall under non-equilibrium state 2. Holzforschung 55: 8792. - doi: 10.1515/HF.2001.014

Cao J, Yu L, You X, Pascal DK (2007). Dielectric properties of copper-ethanolamine treated Chinese fir (Cunninghamia lanceolata Hook.). Forest Study in China 9: 239-245. - doi: 10.1007/s11 632-007-0038-7

Chau TT, Ma E (2015). Moisture adsorption and hygroexpansion of paraffin wax emulsiontreated southern pine (Pinus spp.). Bioresources 10: 2719-2731. - doi: 10.15376/biores.10.2. 2719-2731

Cole K, Cole R (1941). Dispersion and adsorption in dielectrics. Journal of Chemical Physics 9: 341-351. - doi: 10.1063/1.1750906

George G, Joseph K, Nagarajan ER, Jose ET, George KC (2013). Dielectric behaviour of PP/ jute yarn commingled composites: effect of fibre content, chemical treatments, temperature and moisture. Composites Part A: Applied Science and Manufacturing 47: 12-21. - doi: 10.101 6/j.compositesa.2012.11.009

Hou Z, Chen Z, Wright R (2004). Theoretical exploration of factors affecting dielectric constants of masson pine. Holzforschung 58: 418422. - doi: 10.1515/HF.2004.063

Khan MA, Rizvi TZ, Abdullah N, Zaheer Y, Iqbal
MZ, Sadiq S (2000). Dielectrically observed consequences of microbial treatment of wood and bamboo. Holzforschung 54: 335-339. - doi: 10.1515/HF.2000.058

Liu M, Zhong H, Ma E, Liu R (2018). Resistance to fungal decay of paraffin wax emulsion/copper azole compound system treated wood. International Biodeterioration and Biodegradation 129: 61-66. - doi: 10.1016/j.ibiod.2018.01.005 Ma E, Zhao G (2012). Special topics on wood physics. China Forestry Publishing House, Beijing, China, pp. 71-89.

Nelson SO (2004). Agricultural applications of dielectric spectroscopy. Journal of Microwave Power and Electromagnetic Energy 39: 75-85. doi: $10.1080 / 08327823.2004 .11688510$

Norimoto M (1976). Dielectric properties of wood. Wood Research 59/60: 106-152. [online] URL: http://repository.kulib.kyoto-u.ac.jp/dspac e/bitstream/2433/53433/1/KJ00000737481.pdf

Norimoto M, Yamada T (1970). The dielectric properties of wood. IV: On dielectric dispersions of oven-dried wood. Wood Research 50: 36-49. [online] URL: http://repository.kulib.kyo to-u.ac.jp/dspace/handle/2433/53427?locale=en Sahin H, Ay N (2004). Dielectric properties of hardwood species at microwave frequencies. Journal of Wood Science 50: 375-380. - doi: 10.1007/s10086-003-0575-1

Sreekumar PA, Saiter JM, Joseph K, Unnikrishnan G, Thomas S (2012). Electrical properties of short sisal fibre reinforced polyester composites fabricated by resin transfer moulding. Composites Part A: Applied Science and Manufacturing 43: 507-511. - doi: 10.1016/j.compositesa. 2011.11.018

Sugimoto H, Takazawa R, Norimoto M (2005). Dielectric relaxation due to heterogeneous structure in moist wood. Journal of Wood Science 56: 549-553. - doi: 10.1007/s10086-004-068 8-1

Torgovnikov G (1993). Dielectric properties of wood and wood-based material. Springer-Verlag, New York, USA, pp.135-143. - doi: 10.1007/ 978-3-642-77453-9_8

Wang J, Xie G, Li X (2011). Study on water repellent performance improvement of ACQ wood preservative. Guangdong Forest Science and Technology 27: 59-61. [online] URL: http:// en.cnki.com.cn/Article_en/CJFDTOTAL-GDLY201 
103012.htm

Wang J, Tang S, Ma E, Cao J, Wang L (2014). Properties of compound systems of paraffin wax emulsion and copper azole and treated wood. Agriculture Science and Technology 15: 222-224. [online] URL: http://search.proquest. com/openview/42e5c6d1c5c9c7b6afa27b31081a $\mathrm{fabg} / 1$

Wang W, Zhu Y, Cao J, Pascal DK (2016). Monitoring electrical properties of thermally modified wood as a possible tool for quality assessment. Holzforschung 70: 351-359. - doi: 10.1515/ hf-2014-0366
Zhao G, Nishino Y, Nakao T (1994a). Dielectric relaxation of water absorbed on formaldehydetreated wood. Mokuzai Gakkaishi 40: 258-262. Zhao G, Nishino Y, Nakao T (1994b). Dielectric relaxation of water absorbed on acetylated wood. Mokuzai Gakkaishi 40: 571-576.

Zhong H, Wang J, Tang S, Ma E (2014). CAB/New-type paraffin emulsion compound system: study on the mould preservation property of treated wood. Agriculture Science and Technology 15: 2053-2056.

\section{Supplementary Material}

Fig. S1 - Image of dielectric testing machine.

Fig. S2 - Sketch images of dipoles reorientation under oven-dried condition in the alternating electric field.

Fig. S3 - Sketch images of dipoles reorientation under air-dried condition in the alternating electric field.

Link: Liao_2879@supploo1.pdf 